J. clin. Path. (1947), 1, 34.

\title{
FAMILIAL INTESTINAL POLYPOSIS
}

\author{
BY \\ CUTHBERT E. DUKES \\ From St. Mark's Hospital, London
}

(RECEIVED FOR PUBLICATION, FEBRUARY 25, 1947)

Familial polyposis is of interest for its own sake as a sort of pathological curiosity and also in relation to the problem of cancer. The term "polyposis" is used to describe a widespread adenomatous proliferation of the intestinal mucous membrane, leading to the formation of multiple adenomata. It should not be applied to intestinal polyps of different histological structure, such as inflammatory or fibroid polyps, because these exhibit no special tendency to carcinoma, whereas true polyposis undoubtedly does. In fact, intestinal cancer is an almost invariable sequel to familial polyposis.

\section{Clinical Classification of Adenomatous Polyps}

Two clinical types of multiple adenomatous polypi may be distinguished: (1) a familial variety which affects several members of one family and generally manifests itself in adolescence ; and (2) a so-called acquired variety which usually appears later in life and is not hereditary. This classification of intestinal polypi was first suggested by Erdmann and Morris (1925) who pointed out that there are some features in which these two clinical conditions resemble each other and some in which they differ. Both types of polypi tend to malignancy, but in the familial or adolescent variety the polyps are very widely disseminated throughout the rectum and colon, whereas the acquired or adult type is more limited in numbers and extent. Also the liability to cancer is greater in the familial than in the acquired type.

\section{Differentiation of the Familial Type}

Although these points of distinction between the two varieties are of value, they do not always serve to settle at once whether a case of multiple polypi is of the familial or acquired type. In most cases this can only be decided by inquiring carefully into the family history. When this is done there is often ample evidence that near relatives have been similarly affected and the case is obviously of the familial type. In other instances there is nothing to suggest that any near relative has had any complaint which could be attributed to polyposis. Our experience at St. Mark's Hospital is that evidence of a familial character is obtained in about one-third to one-half of all polyposis patients at the time of first diagnosis, and this is in close agreement with the experience of McKenney (1936) and Friedell and Wakefield (1943). However, this is certainly an underestimate of the extent of the familial character, because if the distinction between the familial and the acquired type of polyposis is only to depend on the presence of polypi in other members of a family then obviously the first victim in a family will always be classified as "acquired." Only when subsequent cases have occurred among relatives will the familial character be apparent. For this reason cases provisionally classified as of the acquired type may need 10 be reconsidered if evidence of a familial disposition is discovered later.

\section{Development of Knowledge of Familial Polyposis}

Polyposis is a relatively rare disease, and before the closing years of the nineteenth century nothing was known of its familial character or liability to cancer, though a few descriptions of multiple polypi can be found in the medical literature of that period. Some of the reported cases were probably examples of inflammatory polyps following chronic ulcerative colitis or dysentery ; in fact, it was generally supposed in those days that all polyps were the late result of an inflammatory process. The credit for recognizing the familial character of some forms of polyposis should be given to Harrison Cripps (1882), who sixty-five years ago read a paper before the Pathological Society of London entitled "Two cases of disseminated polypus of the rectum." The interest of this communication lay in the fact that the two patients, a boy of 19 and a girl of 17 , were brother and sister. Within a few years several other examples of familial polyposis were reported, and the fact became established that heredity is an 
important consideration in relation to some intestinal polypi.

Eight years later Handford (1890) also presented a paper before the same society in which he described a case of polyposis in a woman aged 34 who died from cancer of the rectum. Similar cases were soon recorded in other countries and evidence began to accumulate both of the familial character and of liability to cancer.

The introduction of the sigmoidoscope resulted in a rapid advance in knowledge of this disease ; and Lockhart-Mummery, who was one of the first surgeons in England to advocate the more general use of the sigmoidoscope, was also one of the first to publish genealogical trees depicting the transmission of polyposis from one generation to another (Lockhart-Mummery, 1925). His paper illustrated the inheritance of polyposis in three families, and five years later further information about these families and other similar cases was recorded (Dukes, 1930). Since then many more cases have been reported.

\section{Morbid Anatomy and Histology of Polyposis}

In the familial type of polyposis the whole mucosal surface of the colon and rectum is covered with innumerable tumours ranging in size from tiny mammillations, only just visible, up to large pedunculated tumours. The smaller tumours are sessile (Fig. 1), but the larger ones are often attached by a broad strap-like stalk (Fig. 2). The total number of tumours varies considerably. They may cover the whole surface diffusely so that it is hard to find an unaffected patch of mucous membrane, or they may be more sparsely scattered; but there are always large numbers of tumours. The disease generally affects the whole colon and rectum but not the small intestine and stomach, though occasional isolated polyps may be found in the stomach also (Coffey and Bargen, 1939). As a rule, however, the disease ends abruptly in the ileo-caecal junction.

Sections show the tumours to be adenomas in which active epithelial proliferation is in progress. All stages in the development of an adenoma may be noticed, the commonest lesions being small adenomas with a short pedicle (Fig. 3). In between the tumours the intestinal mucous membrane may show patches of hyperplasia.

When examining a case of polyposis a special search must be made for signs of carcinoma. The features which suggest malignancy are darker colour, firmer consistency, and ulceration. The adenomata themselves are often darker in colour than the surrounding mucosa, but a focus of carcinoma makes such a tumour even darker still. Most adenomata feel soft and have a rubber-like consistency, but when malignancy has supervened they feel much harder and more solid. Ulceration is almost invariably a sign of malignancy, and so is induration of the stalk of a pedunculated tumour.

\section{Symptoms and Diagnosis of Polyposis}

In familial polyposis the onset of symptoms is usually insidious and there is at first only slight looseness of the bowels associated with the passage of small quantities of blood and mucus. At first the patient is not ill in the clinical sense. This is a point of distinction between polyposis and polypoid lesions of an inflammatory nature following colitis or dysentery, because in these the initial illness is of a severe character. On the other hand, with familial polyposis the initial symptoms are relatively trivial. For instance, in two cases recently encountered the patients had suffered from symptoms of polyposis for seven years before consulting a doctor.

The final diagnosis of polyposis generally depends on the result of sigmoidoscopic examination, but radiographs are sometimes a valuable aid to diagnosis. Anderson and Marxer (1930) have pointed out that in polyposis the mucosa in general presents a mottled or honeycombed appearance, but frequent examination may be needed to demonstrate this well, and the general routine of the ordinary barium meal may require some modification.

\section{Inheritance of Polyposis}

It is well known that, although cancer itself is not inherited in the ordinary sense of the word, none the less certain families do show a strong predisposition to the development of tumours. In these families tumours of a specific type tend to appear in a specific organ (Macklin, 1935). The simple occurrence of two or more cases of cancer in one family does not of course prove that any inherited predisposition exists. The operation of the law of chance will naturally result in some families having an excess of cancer and others none at all. But, as Weller (1937) has pointed out, there is ample evidence of the existence of some families in which the mass incidence of cancer is significantly in excess of all normal expectations, and he quotes as an example the family originally studied and reported by Warthin. Forty-one out of 174 members of this family attaining the age of 
25 years developed neoplasms. With two exceptions all the cancers were of the gastro-intestinal tract and uterus. No less than 20 of the males had suffered from cancer of the intestinal tract.

Members of polyposis families show no special proclivity to the development of tumours in any other organ of the body than the intestine, and the disease does not usually manifest itself before childhood or puberty although the age at which adenomata develop varies considerably in different families. For the cases we have investigated at St. Mark's Hospital, London, the average age at which adenomata were discovered was 22 years. The youngest patient was 8 and the oldest 45 . There was reason to believe that the tumours had been present for a year or two before they were discovered, so they probably developed at about 20 years of age on the average. Gabriel (1945) states that only rarely has polyposis been noticed in the first decade or after forty years of age. Occasionally, however, cases have been reported which suggest that polypi have been present at birth or developed in infancy. Thus McKenney (1936 and 1939) reports one family in which he sigmoidoscoped four children aged 2, 5, 9, and 11, and found adenomas in each. These tumours seemed to be progressively larger and more numerous as age advanced, and he considered that in these four children polypi had probably been present at birth.

One of the unsolved problems in the pathology of polyposis is whether all or only some members of a family inherit the mysterious defect which manifests itself finally as polyposis. In a decentsized, intelligent, and co-operative polyposis family one can generally get evidence that about half the adult members are or have been affected. The question is whether the at present unaffected individuals are destined to develop the disease later. The only way to answer this conundrum is to watch to see what happens to them. At St. Mark's Hospital we have engaged in this waiting game for more than 20 years and have had the opportunity more than once to observe polypi develop in an individual who at the first sigmoidoscopic examination was certified free from polyps.

A striking example of this is seen in the genealogical tree recorded in Fig. 4. In this chart males are represented by squares, females by circles, and individuals with intestinal tumours (whether adenomas or carcinomas) by black squares or circles respectively. The man recorded as III 1 (indicated by an arrow) is now 60 years of age. His father, grandfather, and at least five of his uncles and aunts died of cancer, and some of them had transmitted polyposis to their descendants. This patient was first examined by
Mr. Lockhart-Mummery at the age of 38 and was found to be free from polypi. He was kept under observation, and six years later, when he was 44 , polypi were first noticed. The patient was quite well aware of the existence of the skeleton in the family cupboard and he kept closely in touch with his medical advisers, which proved to be a good policy for him, because at the age of 56 he developed cancer of the descending colon. This was successfully excised by Mr. Lockhart-Mummery, but three years later at the age of 59 he developed cancer of the rectum, which was dealt with by Mr. Naunton Morgan by perineoabdominal excision. A few months later, at the age of 60 , the patient developed a third cancer at the site of his colostomy, and this was also removed without delay.

This patient's story illustrates the difficulty of deciding whether the defect leading to polyposis is inherited by all or only by some members of a family. On the first occasion when the pedigree of this patient was published (Lockhart-Mummery, 1925) he was represented as unaffected. When further details were published by LockhartMummery and Dukes in 1939 he was recorded as suffering from polyposis. Now the story has unfolded itself still further, and he is recorded as an example of multiple cancer.

This incident also illustrates the fact that a polyposis family group is constantly changing its composition and the proportion of unaffected individuals varies from time to time. McKenney (1939), who has kept careful records of three families for several years, has described tersely the vigilant attitude which must be adopted by the student of the disease. "A polyposis family group history is an ever-changing one," he says, "and the chronicler must not lay aside his typewriter as the story must constantly be rewritten."

There are two ways in which further knowledge may be gained about the transmission of polyposis. One is by patiently observing year by year and recording what happens in polyposis families. The other is by searching for curious and unexpected incidents which may throw light on the problem.

There is, for instance, the family reported by Zahlman in which a woman free from polyposis was married twice (for reference see Dukes, 1930). By her first husband, who was also free from polyposis, she had two children, both of whom were healthy. Her second husband suffered from polyposis, and ultimately died of cancer. By him she had four children, all of whom suffered from polyposis. This proves transmission by the male.

Again, in a family recorded by McKenney (1936), a woman suffering from polyposis was married twice, each of her husbands being free from the disease. 
She had four children, two by each husband, and all four children suffered from polyposis. This proves transmission by the female.

One of the families studied at St. Mark's Hospital is of special interest because of the presence of twins in the second generation. Each of the twins developed polypi about the age of 30 . One was treated by colectomy at the age of 41 and succumbed to the operation : the other also died of intestinal cancer at the age of 41 .

Polyposis patients sometimes ask the question : Who was responsible for first introducing this defect into our family and what is it due to? This, of course, is another unsolved problem, but a clue to it might be obtained if family pedigrees could be traced further back. People generally know something about the health of their parents, but very little about their grandparents and practically nothing about their great-grandparents, so it is seldom possible to trace a complaint through a family for more than two or three generations.

When further data are available it may possibly be found that polyposis results from the chance mating of two individuals, each of whom was destined to die of cancer of the intestine. At any rate it is worth recording that in two of the ten families we have investigated at St. Mark's Hospital the disease appeared in a family in which both father and mother had died of cancer of the rectum or colon. As far as could be ascertained this was the starting point of the disease in these two families.

\section{Relationship of Polyposis to Carcinoma}

Malignant disease secondary to familial polyposis is characterized by its early age of onset and the fact that more than one primary focus of carcinoma may be present. Among the general popu- lation it is rare for cancer of the rectum or colon to develop before the age of 40 , but in families affected by polyposis it develops in the thirties or even earlier. The age at death from intestinal cancer in polyposis families is younger by about twenty years than the average age of death from intestinal cancer in the general population. There is considerable variation in different families, but in most cases it may be said that polypi may be expected before the age of 20 and cancer is liable to manifest itself some ten to fifteen years later.

Polyposis is not a familial disease which is likely to spread and become more prevalent: on the contrary polyposis families tend to die out. - That is because cancer so frequently develops before the age of marriage and because even those who do marry die young. Moreover there seems to be a tendency for malignant disease to begin at an earlier age-period in each succeeding generation.

The treatment of polyposis presents a difficult problem. Constant medical supervision is necessary so that a radical excision may be undertaken as soon as malignancy is detected. No other method of treatment than surgery has any permanent effect on the course of the disease.

\section{REFERENCES}

Anderson, J. H., and Marxer; O. A. (1930). Brit. J. Surg., 17, 451. Coffey, R. J., and Bargen, J. A. (1939). Surg. Gynec. Obstet., 69, 136. Cripps, W. H. (1882). Trans. Path. Soc. Lond., 33, 165.

Dukes, C. E. (1930). Cancer Rev., 5, 241.

Erdmann, J. F., and Morris, J. H. (1925). Surg. Gynec. Obstet., $40,460$.

Friedell, M. T., and Wakefield, E. G. (1943). J. Amer. med. Ass., $121,830$.

Gabriel, W. B. (1945). The Principles and Practice of Rectal Surgery, 3rd ed., p. 267. London.

Handford, H. (1890). Trans. Path. Soc. Lond., 41, 133.

Lockhart-Mummery, J. P. (1925). Lancet, 1, 427.

Lockhart-Mummery, J. P., and Dukes, C. E. (1939). Lancet, $2,586$.

McKenney, D. C. (1936). J. Amer. med. Ass., 107, 1871.

McKenney, D. C. (1939). Amer. J. Surg., 46, 204.

Macklin, M. T. (1935). Edinb. med. J., 42, 49.

Weller, C. V. (1937). Amer. J. Cancer, 30, 39. 


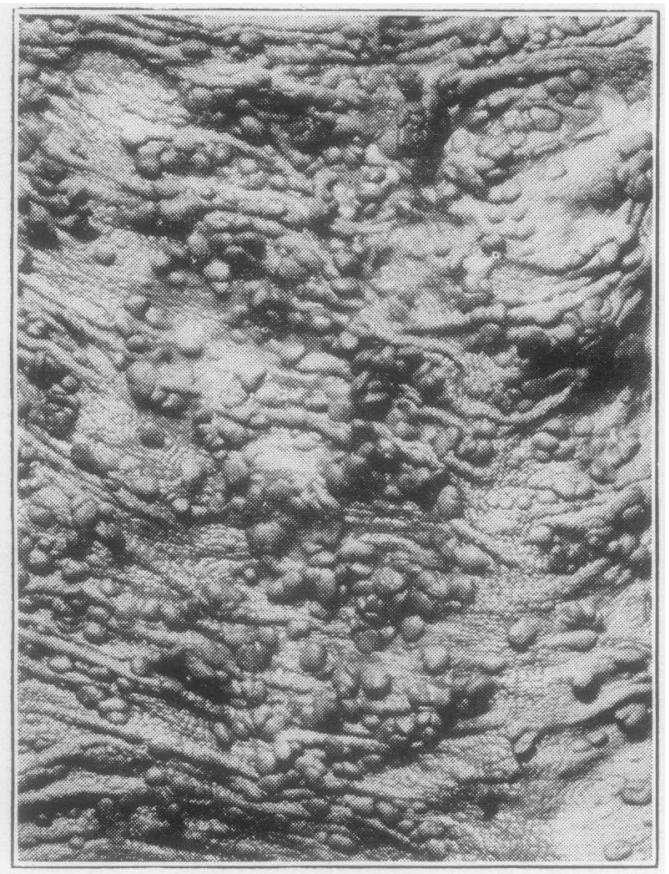

FIG. 1.-Surface view of mucous membrane of colon in familial polyposis, showing sessile adenomata.

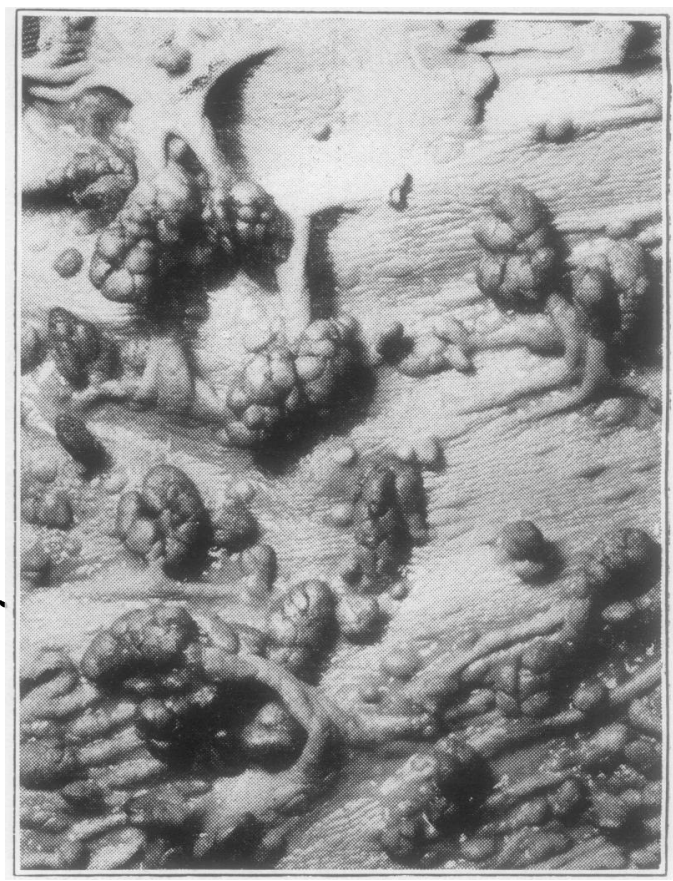

FIG. 2.-Pedunculated adenomata in familial intestinal polyposis.
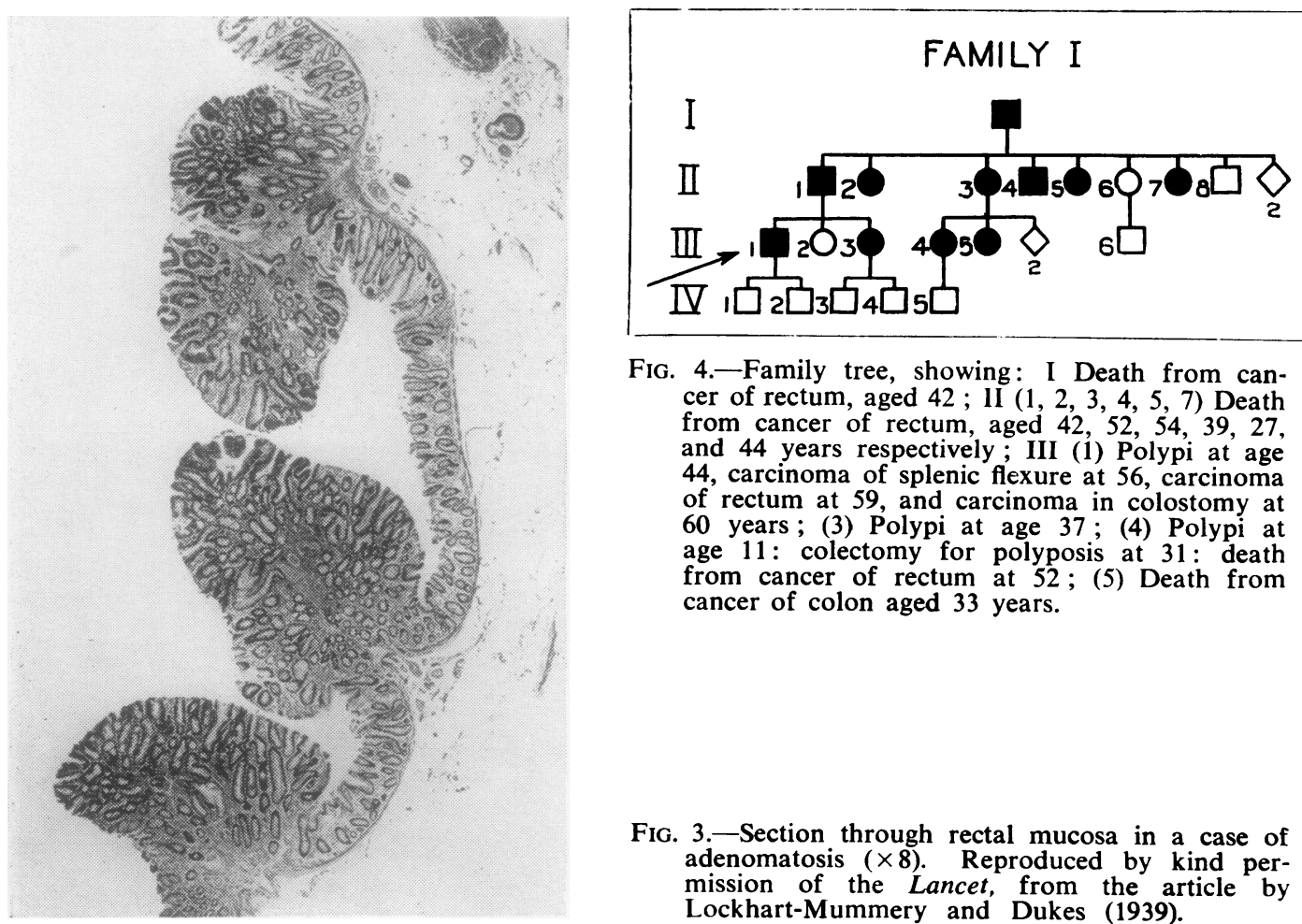

Fig. 4.-Family tree, showing: I Death from cancer of rectum, aged 42 ; II $(1,2,3,4,5,7)$ Death from cancer of rectum, aged $42,52,54,39,27$, and 44 years respectively; III (1) Polypi at age 44 , carcinoma of splenic flexure at 56, carcinoma of rectum at 59, and carcinoma in colostomy at 60 years; (3) Polypi at age 37 ; (4) Polypi at age 11: colectomy for polyposis at 31 : death from cancer of rectum at 52 ; (5) Death from cancer of colon aged 33 years.

FIG. 3.- Section through rectal mucosa in a case of adenomatosis $(\times 8)$. Reproduced by kind permission of the Lancet, from the article by Lockhart-Mummery and Dukes (1939). 